\title{
Backbone chemical shift assignment and dynamics of the N-terminal domain of ClpB from Francisella tularensis type VI secretion system
}

\author{
Ameeq UI Mushtaq ${ }^{1} \cdot$ Jörgen Ådén ${ }^{1} \cdot$ Athar Alam $^{2} \cdot$ Anders Sjöstedt $^{2} \cdot$ Gerhard Gröbner $^{1}[$
}

Received: 13 October 2021 / Accepted: 22 December 2021 / Published online: 5 January 2022

(c) The Author(s) 2022

\begin{abstract}
The Hsp100 family member ClpB is a protein disaggregase which solubilizes and reactivates stress-induced protein aggregates in cooperation with the DnaK/Hsp70 chaperone system. In the pathogenic bacterium Francisella tularensis, ClpB is involved in type VI secretion system (T6SS) disassembly through depolymerization of the IglA-IglB sheath. This leads to recycling and reassembly of T6SS components and this process is essential for the virulence of the bacterium. Here we report the backbone chemical shift assignments and ${ }^{15} \mathrm{~N}$ relaxation-based backbone dynamics of the $\mathrm{N}$-terminal substrate-binding domain of ClpB (1-156).
\end{abstract}

Keywords NMR resonance assignment $\cdot{ }^{15} \mathrm{~N}$ relaxation $\cdot \mathrm{ClpB}$ chaperone $\cdot$ Type VI secretion system · Francisella tularensis

\section{Biological context}

$\mathrm{ClpB}$ is a member of ring-forming AAA + family ATPases that cooperates together with the DnaK/Hsp70 system to reactivate stress-denatured aggregated proteins. ClpB, like other Hsp100 family members, has a homohexameric structure. The monomer of $\mathrm{ClpB}$ comprises four domains: an N-terminal domain (NTD) important for substrate recognition and binding, the first nucleotide binding domain (NBD-1), the flexible middle domain (MD), and a second nucleotide binding domain (NBD-2) (Alam et al. 2021) as shown in Fig. 1A. The physiological role of $\mathrm{ClpB}$ under different conditions has been extensively studied since it provides protection against stress conditions, e.g. heat, low $\mathrm{pH}$, osmotic and oxidative stress, ethanol, and nutrient starvation. ClpB-deficient mutants demonstrate tremendously decreased survival upon exposure to these stresses (Meibom et al. 2008; Krajewska et al. 2017; Tripathi et al. 2020; Glaza et al. 2021). ClpB is therefore critical for survival and infectivity of a broad range of clinically relevant microorganisms.

Gerhard Gröbner

gerhard.grobner@chem.umu.se

1 Department of Chemistry, University of Umeå, 90187 Umeå, Sweden

2 Department of Clinical Microbiology, University of Umeå, 90187 Umeå, Sweden
Besides its role in solubilizing stress-induced protein aggregates, a role of $\mathrm{ClpB}$ in type VI secretion (T6S) has recently been reported in the highly pathogenic intracellular bacterium Francisella tularensis that infects and replicates mainly inside macrophages and causes the disease tularemia in a large number of mammalian species (Brodmann et al. 2017; Alam et al. 2020). A recent report suggests that ClpB apparently serves as a functional homolog of $\mathrm{ClpV}$ and it harnesses energy generated by the hydrolysis of ATPs and it is required for depolymerization of the T6SS sheath and the subsequent recycling and reassembly of the T6SS components. Therefore, the deletion of $\operatorname{clpB}$ leads to significantly reduced level of T6S and complete attenuation of $F$. tularensis in mice (Alam et al. 2018, 2020).

Functional $\mathrm{ClpB}$ orthologs are absent in mammals, including Homo sapiens, thus $\mathrm{ClpB}$ has the potential to serve as drug target for the development of novel antimicrobials. Since $\mathrm{ClpB}$ is an essential factor in bacterial stress response and pathogen virulence, inhibition of $\mathrm{ClpB}$ might suppress infectivity and the survival of invading pathogens. Here we present the backbone chemical shift assignments and dynamics of the $\mathrm{N}$-terminal substrate binding domain of ClpB (1-156) that binds to the IglA-IglB sheath which is important for recycling and reassembly, and essential for the virulence of the bacterium, and can therefore be a potential drug target. 
Fig. 1 A Schematic picture showing the domain organization of ClpB from F. tularensis, comprising of four domains: $\mathrm{N}$-terminal domain (NTD), two nucleotide-binding domains (NBD-1 and NBD2 ), and middle domain (MD). B ${ }^{1} \mathrm{H}-{ }^{15} \mathrm{~N}$ HSQC spectrum of ${ }^{15} \mathrm{~N} /{ }^{13} \mathrm{C}$-labeled $1.7 \mathrm{mM}$ NTD ClpB (1-156) in $20 \mathrm{mM} \mathrm{NaPi}$, $20 \mathrm{mM} \mathrm{NaCl}(\mathrm{pH} 6.5)$ and $10 \%$ (v/v) $\mathrm{D}_{2} \mathrm{O}$ buffer showing the assignment of backbone amides indicated with one-letter codes for amino acids and the residue numbers in blue. All spectra were acquired at $310 \mathrm{~K}$ at $850 \mathrm{MHz}{ }^{1} \mathrm{H}$ frequency
A

B

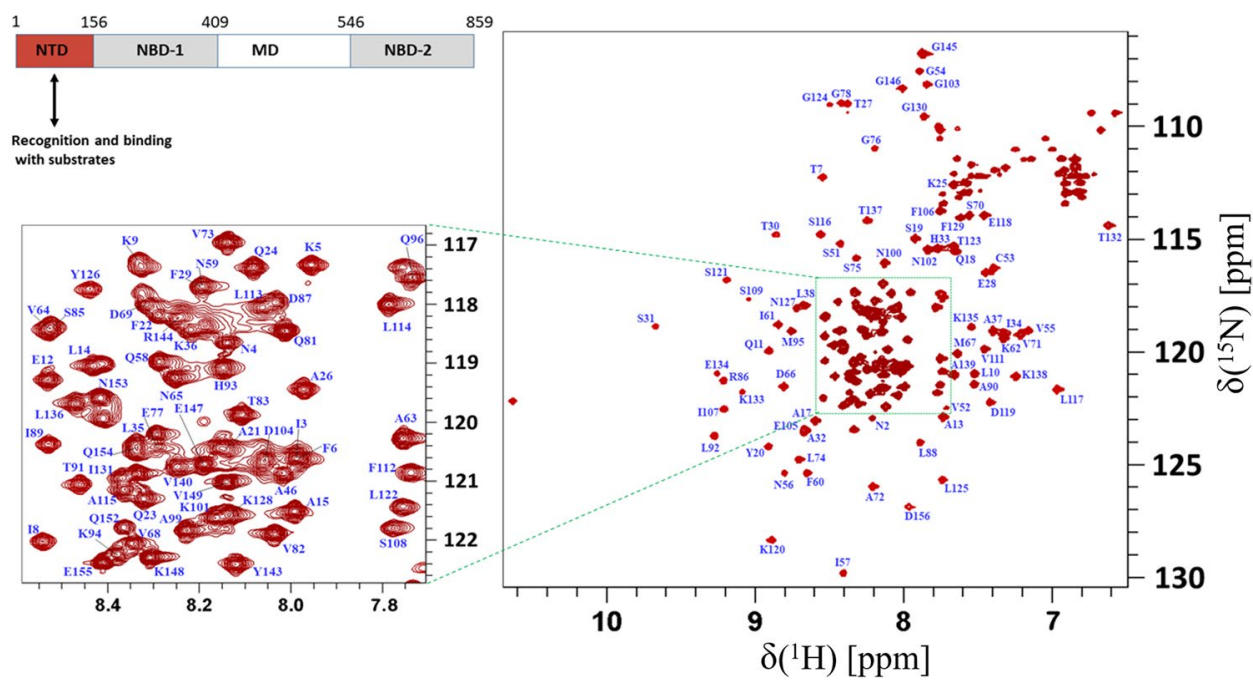

\section{Methods and experiments}

\section{Protein expression and purification of isotope-labelled NTD ClpB(1-156)}

The first $156 \mathrm{~N}$-terminal residues of the $\mathrm{ClpB}$ chaperone from $F$. tularensis [NTD ClpB (1-156)] were cloned into the pET-His1a expression vector using essentially the same strategy as reported before (Alam et al. 2020). Expression was initiated by transforming $1 \mu \mathrm{l}$ of plasmid into $100 \mu \mathrm{l}$ of Escherichia coli BL21 (DE3) competent cells, and plated on agar plates with $50 \mu \mathrm{g} / \mathrm{ml}$ kanamycin. The following day, cells were transferred into a pre-culture consisting of $20 \mathrm{ml} 1 \times \mathrm{LB}$ with $50 \mu \mathrm{g} / \mathrm{ml}$ kanamycin, and further grown at $37{ }^{\circ} \mathrm{C}$ overnight. $10 \mathrm{ml}$ of fresh culture was transferred into $\mathrm{M} 9$ medium prepared (per liter) as following: $6 \mathrm{~g} \mathrm{Na}_{2} \mathrm{HPO}_{4}, 3 \mathrm{~g} \mathrm{KH}_{2} \mathrm{PO}_{4}, 0.5 \mathrm{~g} \mathrm{NaCl}, 6.25 \mathrm{~g}$ glucose, $1 \mathrm{~g} \mathrm{NH}_{4} \mathrm{Cl}, 11 \mathrm{mg} \mathrm{CaCl} 2,1 \mathrm{~g} \mathrm{MgSO}_{4} \cdot 7 \mathrm{H}_{2} \mathrm{O}$, and trace elements $\left(1 \mathrm{ml}\right.$ of $50 \mathrm{mM} \mathrm{FeCl}{ }_{3}, 20 \mathrm{mM} \mathrm{CaCl}_{2}$, $10 \mathrm{mM} \mathrm{MnCl}_{2}, 10 \mathrm{mM} \mathrm{ZnSO}_{4}, 2 \mathrm{mM} \mathrm{CoCl}_{2}, 2 \mathrm{mM} \mathrm{CuCl}_{2}$, $2 \mathrm{mM} \mathrm{NiCl}_{2}, 2 \mathrm{mM} \mathrm{Na}_{2} \mathrm{MoO}_{4}$ and $2 \mathrm{mM} \mathrm{H}_{3} \mathrm{BO}_{3}$ per liter medium). The $\mathrm{pH}$ was adjusted to 7.1 with $\mathrm{NaOH}$ and sterile filtrated using a $20 \mu \mathrm{m}$ sterile filter prior to use. For ${ }^{15} \mathrm{~N}$ labeling, $1 \mathrm{~g}$ of $\mathrm{NH}_{4} \mathrm{Cl}$ was replaced with ${ }^{15} \mathrm{NH}_{4} \mathrm{Cl}$, and for ${ }^{15} \mathrm{~N} /{ }^{13} \mathrm{C}$ labeling, the glucose was also substituted with $1.2 \mathrm{~g}{ }^{13} \mathrm{C}$ glucose per liter M9 media (both from Cambridge Isotope Laboratories, Inc., Tewksbury, MA, USA). The culture was supplemented with $50 \mu \mathrm{g} / \mathrm{ml}$ kanamycin and grown at $37{ }^{\circ} \mathrm{C}$ until $\mathrm{OD}_{600}=0.6$, followed by induction with $1 \mathrm{mM}$ IPTG. Then the temperature was lowered to $23{ }^{\circ} \mathrm{C}$, and cells were further grown over night. The next day cells were centrifuged at $4400 \times \mathrm{g}$ for $30 \mathrm{~min}$, and the pellet resuspended in $20 \mathrm{mM}$ Tris, $100 \mathrm{mM} \mathrm{NaCl}, 10 \mathrm{mM}$ imidazole, $\mathrm{pH} 7.8$, and sonicated on ice using a Branson 450 Digital Sonifier (BRANSON Ultrasonics Corporation, USA). Cells were centrifuged at $48,000 \times \mathrm{g}$ for $30 \mathrm{~min}$, and the presence of NTD ClpB could be verified as soluble protein on an SDS-PAGE gel. The soluble fraction was filtered through a $45 \mu \mathrm{m}$ filter and loaded onto a HisPrep FF 16/10 nickel affinity column (GE Healthcare), equilibrated with $20 \mathrm{mM}$ Tris, $100 \mathrm{mM} \mathrm{NaCl}, 10 \mathrm{mM}$ imidazole, $\mathrm{pH}$ 7.8. NTD ClpB (1-156) protein was eluted using a linear gradient containing $20 \mathrm{mM}$ Tris, $100 \mathrm{mM} \mathrm{NaCl}, 500 \mathrm{mM}$ imidazole, $\mathrm{pH}$ 7.8. Selected fractions were dialyzed over night against $50 \mathrm{mM}$ Tris, $50 \mathrm{mM} \mathrm{NaCl}, 1 \mathrm{mM}$ DTT, $0.5 \mathrm{mM}$ EDTA, $\mathrm{pH}$ 8.0. The His-tag was then cleaved off using TEV protease (purchased in-house from the Protein Expertise Platform at Umeå University, Sweden), added in a 1:100 (w/w) ratio, and incubated at $4{ }^{\circ} \mathrm{C}$ for $48 \mathrm{~h}$. The protein was then dialyzed once more against $20 \mathrm{mM}$ Tris, $100 \mathrm{mM} \mathrm{NaCl}, 10 \mathrm{mM}$ imidazole, $\mathrm{pH} \mathrm{7.8,} \mathrm{and} \mathrm{then}$ loaded on the HisPrep FF 16/10 nickel affinity column, equilibrated with the same buffer. Pure NTD ClpB will pass through the column, since it is lacking the His-tag, which resulted in pure protein (SI Fig. 1A). A final dialysis step was performed to buffer exchange the protein into the proper buffer for NMR analysis $(20 \mathrm{mM} \mathrm{NaPi}, 20 \mathrm{mM}$ $\mathrm{NaCl}, \mathrm{pH} 6.5)$. The final yield of pure NTD ClpB (1-156) protein was very high, where typical yields of ${ }^{15} \mathrm{~N}$ enriched protein reached $200 \mathrm{mg}$ per liter of M9 culture.

\section{NMR spectroscopy}

For NMR measurements, NTD ClpB (1-156) was concentrated to $1.7 \mathrm{mM}$ in NMR buffer $(20 \mathrm{mM} \mathrm{NaPi}, 20 \mathrm{mM} \mathrm{NaCl}$ at $\mathrm{pH} 6.5)$ and $\mathrm{D}_{2} \mathrm{O}[10 \%(\mathrm{v} / \mathrm{v})]$ was added to all NMR samples for the field-frequency lock. All NMR spectra were 
recorded on an Avance III 850-MHz NMR spectrometer equipped with a triple-resonance cryogenic probe (Bruker, Germany). NMR spectra were processed using NMRPipe and NMRDraw software (Delaglio et al. 1995) and visualized and analyzed using CcpNMR 2.4.2 (Vranken et al. 2005). For backbone assignment, a series of triple-resonance experiments using $\mathrm{HNCA}, \mathrm{HN}(\mathrm{CO}) \mathrm{CA}, \mathrm{CBCANH}$, $\mathrm{CBCA}(\mathrm{CO}) \mathrm{NH}, \mathrm{HNCO}$, and $\mathrm{HN}(\mathrm{CA}) \mathrm{CO}$ were performed at $310 \mathrm{~K}$ using uniformly $\left[{ }^{13} \mathrm{C} /{ }^{15} \mathrm{~N}\right]$-labeled NTD ClpB (1-156). Assigned chemical shifts were directly referenced against 4,4-dimethyl-4-silapentane-1-sulfonic acid (DSS) for the ${ }^{1} \mathrm{H}$ atoms, whereas ${ }^{13} \mathrm{C}$ and ${ }^{15} \mathrm{~N}$ atoms were referenced indirectly as suggested (http://www.bmrb.wisc.edu). ${ }^{1} \mathrm{H}_{\mathrm{N}}$, ${ }^{15} \mathrm{NH},{ }^{13} \mathrm{C} \alpha,{ }^{13} \mathrm{C} \beta$, and ${ }^{13} \mathrm{C}$ chemical-shift data was used for secondary structure prediction with TALOS + (Shen et al. 2009). Secondary structure comparison was made with NTD $\mathrm{ClpV}$ homolog crystal structures, sequence alignments of NTD ClpB (F. tularensis) with NTD ClpV homologs (E. coli and V. cholerae) are shown in SI Fig. 1B.

For measurements of ${ }^{15} \mathrm{~N}$-relaxation parameters, the $\mathrm{T}_{1}, \mathrm{~T}_{2}, \mathrm{~T}_{1 \rho}$, and ${ }^{1} \mathrm{H}^{-15} \mathrm{~N}$-heteronuclear nuclear Overhauser effects (NOEs) interleaved ${ }^{1} \mathrm{H}_{-}{ }^{15} \mathrm{~N}$-correlation spectra for the ${ }^{15} \mathrm{~N}$-labeled $\mathrm{ClpB}(1-156)$ were measured as previously described. (Dayie and Wagner 1994; Farrow et al. 1994) Backbone ${ }^{15} \mathrm{~N} \mathrm{~T}_{1}$ values were determined from the spectra using delay durations of 50, 100, 200, 500, 800, 1000, 1200 and $1500 \mathrm{~ms} .{ }^{15} \mathrm{~N} \mathrm{~T}_{2}$ values were determined from the spectra using delay durations of $16.96,33.92,50.88,84.8$, 101.76, 118.72, 135.68, 152.64, $2 \times 169.6,186.56,203.52$, 220.48, 254.4, and $288.32 \mathrm{~ms}$ (Farrow et al. 1994), ${ }^{15} \mathrm{~N} \mathrm{~T}_{1 \rho}$ values were determined from the spectra using spin-lock durations of 8, 24, 40, 60, 80, 120, 160, 180, 200 and $302 \mathrm{~ms}$ at $1.92 \mathrm{kHz}$ spin-lock strength. Relaxation delays of $3 \mathrm{~s}$ and $2 \mathrm{~s}$ were used for $\mathrm{T}_{1}$ and $\mathrm{T}_{2}$ or $\mathrm{T}_{1 \rho}$ experiments, respectively. Steady-state ${ }^{15} \mathrm{~N}$ - ${ }^{1} \mathrm{H}$-heteronuclear NOE spectra were measured with either $5 \mathrm{~s}$ delays between each free-induction decay or $2 \mathrm{~s}$ delays, followed by a $3 \mathrm{~s}$ series of $120^{\circ}$ nonselective ${ }^{1} \mathrm{H}$ pulses as previously described (Dayie and Wagner 1994). $\mathrm{T}_{1}, \mathrm{~T}_{2}, \mathrm{~T}_{1 \rho}$ and ${ }^{15} \mathrm{~N}-{ }^{1} \mathrm{H}$ NOE experiments were performed with time-domain sizes of $256 \times 2048$ complex points and sweep widths of $11,029.4$ and $2240.0 \mathrm{~Hz}$ along the ${ }^{1} \mathrm{H}$ and ${ }^{15} \mathrm{~N}$ dimensions, respectively, with 8 scans for $\mathrm{T}_{1}, \mathrm{~T}_{2}$ or $\mathrm{T}_{1 \rho}$ and 24 scans for the ${ }^{15} \mathrm{~N}-{ }^{1} \mathrm{H}$ NOE experiment. All ${ }^{15} \mathrm{~N}$-relaxation experiments were performed at $310 \mathrm{~K}$.

For ${ }^{15} \mathrm{~N}$-relaxation data analysis the NMRFAM-SPARKY (v 1.470) (Lee et al. 2015) was used. Peak heights of the ${ }^{1} \mathrm{H}-{ }^{15} \mathrm{~N}$ cross-peaks in the $\mathrm{T}_{1}, \mathrm{~T}_{2}$ and $\mathrm{T}_{1 \rho}$ spectra were measured using a peak-picking routine of SPARKY and fitted to a single exponential-decay function using the Curvefit module in SPARKY. Errors in $\mathrm{T}_{1}, \mathrm{~T}_{2}$ and $\mathrm{T}_{1 \rho}$ were estimated from the fittings using 500 Monte Carlo simulations. ${ }^{15} \mathrm{~N}-{ }^{1} \mathrm{H}$-heteronuclear NOE values were calculated from the ratio of peak intensities, $I_{\text {sal }} / I_{\text {unsat }}$, where $I_{\text {sat }}$ and $I_{\text {unsat }}$ represent the intensities of peaks in saturated and unsaturated spectra, respectively. ${ }^{15} \mathrm{~N}$-relaxation rates were measured for the resolved and assigned resonances of the NTD ClpB (1-156). For the model-free analysis, parameters of internal motion were determined according to model-free formalism (Lipari and Szabo 1982a, b) using Modelfree4 software (v4.20; Columbia University, New York, NY, USA). Using only residues with $\mathrm{hnNOE}>0.25, \mathrm{~T}_{1}, \mathrm{~T}_{2}$, and NOE-relaxation data were optimized with an isotropic diffusion model using 500 Monte Carlo simulations, assuming an internuclear distance $\left(\mathrm{r}_{\mathrm{NH}}\right)$ of $1.02 \AA$ and chemical-shift anisotropy of $-160 \mathrm{ppm}$ for the ${ }^{15} \mathrm{~N}$ nucleus, generalized order parameter values were obtained (Mandel et al. 1995).

\section{Extent of assignments and data deposition}

Backbone amide resonances in the ${ }^{1} \mathrm{H}-{ }^{15} \mathrm{~N}$ HSQC spectrum of NTD ClpB (1-156) have been assigned (Fig. 1B). A total of $91 \%$ of the ${ }^{13} \mathrm{C} \alpha, 86.5 \%$ of the ${ }^{13} \mathrm{C} \beta, 87.2 \%$ of the ${ }^{13} \mathrm{C}^{\prime}$ and $88.2 \%$ of the ${ }^{1} \mathrm{HN},{ }^{15} \mathrm{~N}$ backbone resonances were assigned for NTD ClpB (1-156). The N/HN resonances were absent for residues 40-50 in the spectra, presumably due to conformational exchange or rapid solvent-exchange or both (Explanation in ${ }^{15} \mathrm{~N}$ backbone dynamics section). The assignments have been deposited in the BioMagResBank with accession code 51,087. These assignments of the substrate binding domain of $\mathrm{ClpB}$ will help to identify binding sites required for the recognition of type VI secretion sheath proteins IglAIglB and potential drug candidates.

\section{Secondary structure of NTD ClpB}

Secondary structure of NTD ClpB in solution was determined based on resonance assignments as an input in TALOS + (Shen et al. 2009). Overall the secondary structure is similar to ClpB homologs (ClpV, homolog of $E$. coli) as shown by the comparison of TALOS + based secondary structure of NTD ClpB with the secondary structure based on the crystal structure of the NTD ClpB homolog ClpV(PDB ID: 4HH6) as shown in (Fig. 2A).

\section{${ }^{15} \mathrm{~N}$ backbone dynamics of NTD ClpB (1-156)}

We identified the flexible regions of the substrate binding NTD ClpB (1-156) using ${ }^{15} \mathrm{~N}$ backbone relaxation experiments. Figure 2B shows the lower heteronuclear NOE values for residues 75-82 which correspond to the loop region in ClpB homologs. The overall correlation time of NTD ClpB (1-156) was $7.52 \mathrm{~ns}$ at $310 \mathrm{~K}$ calculated from the $\mathrm{R}_{2} /$ $\mathrm{R}_{1}$ ratios assuming an isotropic diffusion tensor (Kay et al. 1989). Backbone NH dynamics of NTD ClpB (1-156) were also characterized in terms of generalized order parameter 
A

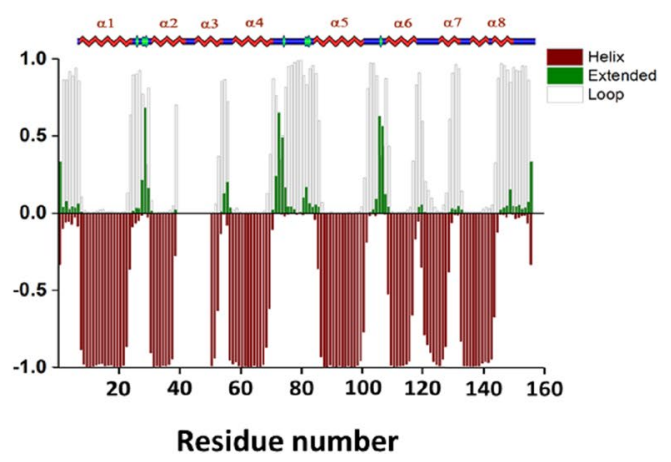

B

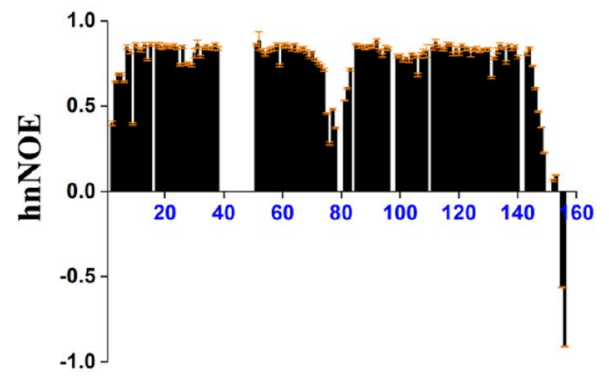

Fig. 2 A TALOS + based secondary structure from assigned chemical shift data of NTD ClpB (1-156), on the top comparison is shown with the secondary structure of NTD ClpV (homolog of E. coli) observed in the X-ray crystal structure (PDB ID: 4HH6). Maroon, green, and

$\left(\mathrm{S}^{2}\right)$ values using the model-free formalism (Lipari and Szabo 1982a, b) with the assumption of isotropic rotational diffusion (Fig. 3D). $R_{2}$ and $R_{1}$ values are also shown (Fig. 3A, D) along the residue number. Comparison of $\mathrm{R}_{1 \rho}$ and $R_{2}$ values near the invisible-fragment residues $40-50$ shows the contributions from exchange (Fig. 3C, D). Most backbone residues of NTD ClpB are rigid (Fig. 2B). The gray-white bars indicate propensities for helix, $\beta$-strand, and randomcoil conformations, respectively. B Plot of the backbone ${ }^{15} \mathrm{~N}-{ }^{1} \mathrm{H}$ heteronuclear NOEs values of NTD ClpB (1-156) plotted along the residue number. Error bars are placed on top of the bar graphs

only flexible parts with increased amplitude of motions on the picosecond-to-nanosecond time scale were seen for residues 75-82 (which corresponds to the loop region in homologs $\mathrm{ClpV}$ ), and also the residues from the far N-terminal and C-terminal ends of the NTD ClpB sequence (Figs. 2B, 3B) were very flexible.
A

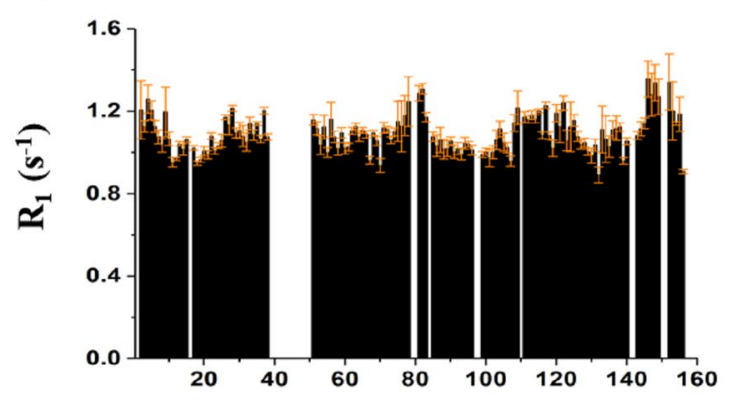

C

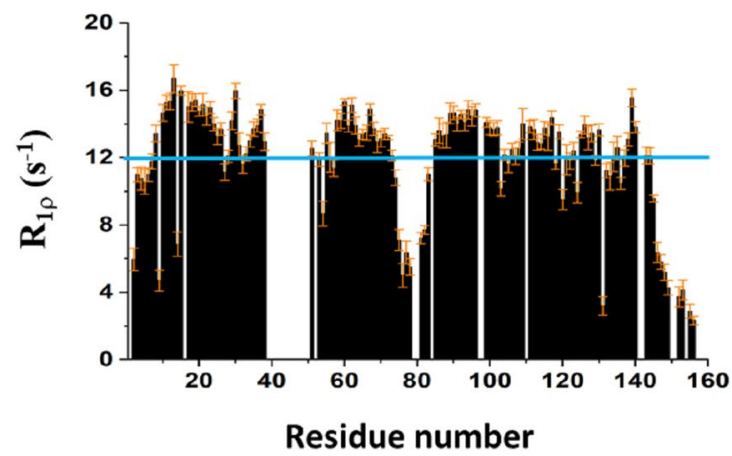

B

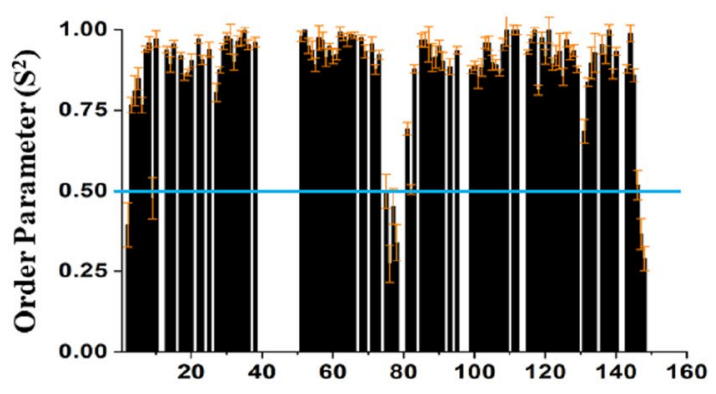

D

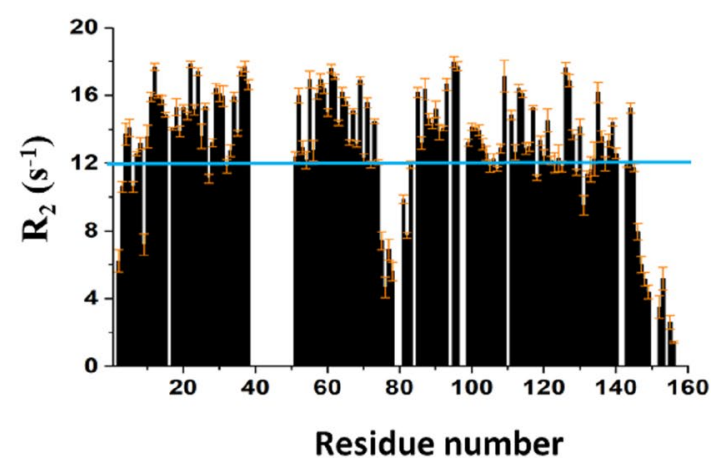

ted along the residue number. Error bars are placed on top of the bar graphs. All ${ }^{15} \mathrm{~N}$ relaxation data were acquired at $310 \mathrm{~K}$ and $850 \mathrm{MHz}$ ${ }^{1} \mathrm{H}$ frequency 
Supplementary Information The online version contains supplementary material available at https://doi.org/10.1007/s12104-021-10062-3.

Acknowledgements GG and AS acknowledge financial support from the Swedish Research Council, the Swedish Cancer Foundation, the Kempe Foundation, the Knut and Alice Wallenberg Foundation ('NMR for Life' Programme). We thank The Protein Expertise Platform (PEP) at Umeå University for providing plasmid and reagents for protein overexpression and purification. NMR experiments were performed at the national ScilifeLab NMR facility at Umeå University.

Author contributions All authors: (1) made substantial contributions to concept and design of work; or the protein production, NMR acquisition and data analysis and interpretation; (2) drafted or revised the work and approved the final version to be published.

Data availability The backbone ${ }^{1} \mathrm{H},{ }^{13} \mathrm{C}$, and ${ }^{15} \mathrm{~N}$ chemical shifts and ${ }^{15} \mathrm{~N}$ relaxation data have been deposited in the BioMagResBank (http:// www.bmrb.wisc.edu/) under the accession number 51087.

\section{Declarations}

Conflict of interest The authors declare they have no conflict of interest.

Open Access This article is licensed under a Creative Commons Attribution 4.0 International License, which permits use, sharing, adaptation, distribution and reproduction in any medium or format, as long as you give appropriate credit to the original author(s) and the source, provide a link to the Creative Commons licence, and indicate if changes were made. The images or other third party material in this article are included in the article's Creative Commons licence, unless indicated otherwise in a credit line to the material. If material is not included in the article's Creative Commons licence and your intended use is not permitted by statutory regulation or exceeds the permitted use, you will need to obtain permission directly from the copyright holder. To view a copy of this licence, visit http://creativecommons.org/licenses/by/4.0/.

\section{References}

Alam A et al (2018) ClpB mutants of Francisella tularensis subspecies holarctica and tularensis are defective for type VI secretion and intracellular replication. Sci Rep 8(1):11324

Alam A et al (2020) Dissociation between the critical role of ClpB of Francisella tularensis for the heat shock response and the DnaK interaction and its important role for efficient type VI secretion and bacterial virulence. Plos Pathog. https://doi.org/10.1371/journ al.ppat. 1008466
Alam A et al (2021) The role of ClpB in bacterial stress responses and virulence. Front Mol Biosci 8:668910

Brodmann $\mathrm{M}$ et al (2017) Francisella requires dynamic type VI secretion system and $\mathrm{ClpB}$ to deliver effectors for phagosomal escape. Nat Commun 8:15853

Dayie KT, Wagner G (1994) Relaxation-rate measurements for N-15-H-1 groups with pulsed-field gradients and preservation of coherence pathways. J Magn Reson Ser A 111(1):121-126

Delaglio F et al (1995) NMRPipe: a multidimensional spectral processing system based on UNIX pipes. J Biomol NMR 6(3):277-293

Farrow NA et al (1994) Backbone dynamics of a free and phosphopeptide-complexed Src homology 2 domain studied by 15N NMR relaxation. Biochemistry 33(19):5984-6003

Glaza P et al (2021) Repurposing p97 inhibitors for chemical modulation of the bacterial ClpB-DnaK bichaperone system. J Biol Chem 296:100079

Kay LE et al (1989) Backbone dynamics of proteins as studied by $15 \mathrm{~N}$ inverse detected heteronuclear NMR spectroscopy: application to staphylococcal nuclease. Biochemistry 28(23):8972-8979

Krajewska J et al (2017) Characterization of the molecular chaperone $\mathrm{ClpB}$ from the pathogenic spirochaete Leptospira interrogans. PLoS ONE 12(7):e0181118

Lee W et al (2015) NMRFAM-SPARKY: enhanced software for biomolecular NMR spectroscopy. Bioinformatics 31(8):1325-1327

Lipari G, Szabo A (1982a) Model-free approach to the interpretation of nuclear magnetic-resonance relaxation in macromolecules. 1 . Theory and range of validity. J Am Chem Soc 104(17):4546-4559

Lipari G, Szabo A (1982b) Model-free approach to the interpretation of nuclear magnetic-resonance relaxation in macromolecules. 2. Analysis of experimental results. J Am Chem Soc 104(17):4559-4570

Mandel AM et al (1995) Backbone dynamics of Escherichia coli ribonuclease HI: correlations with structure and function in an active enzyme. J Mol Biol 246(1):144-163

Meibom KL et al (2008) The heat-shock protein ClpB of Francisella tularensis is involved in stress tolerance and is required for multiplication in target organs of infected mice. Mol Microbiol 67(6):1384-1401

Shen $Y$ et al (2009) TALOS plus: a hybrid method for predicting protein backbone torsion angles from NMR chemical shifts. J Biomol NMR 44(4):213-223

Tripathi $\mathrm{P}$ et al (2020) ClpB is an essential stress regulator of Mycobacterium tuberculosis and endows survival advantage to dormant bacilli. Int J Med Microbiol 310(3):151402

Vranken WF et al (2005) The CCPN data model for NMR spectroscopy: development of a software pipeline. Proteins 59(4):687-696

Publisher's Note Springer Nature remains neutral with regard to jurisdictional claims in published maps and institutional affiliations. 